\title{
Molecular spectrum of TP53 mutations in plasma cell dyscrasias by next generation sequencing: an Italian cohort study and overview of the literature
}

\author{
Marta Lionetti ${ }^{1}$, Marzia Barbieri ${ }^{2}$, Martina Manzoni ${ }^{1}$, Sonia Fabris ${ }^{2}$, Cecilia Bandini ${ }^{2}$, \\ Katia Todoerti ${ }^{3}$, Filomena Nozza ${ }^{3}$, Davide Rossi ${ }^{4}$, Pellegrino Musto ${ }^{3}$, Luca Baldini ${ }^{1,2}$, \\ Antonino Neri ${ }^{1,2}$ \\ ${ }^{1}$ Department of Oncology and Hemato-Oncology, University of Milan, Milan, Italy \\ ${ }^{2}$ Hematology Unit, Fondazione IRCCS Ca' Granda, Ospedale Maggiore Policlinico, Milan, Italy \\ ${ }^{3}$ Laboratory of Pre-Clinical and Translational Research, IRCCS-CROB, Referral Cancer Center of Basilicata, Rionero in \\ Vulture (PZ), Italy \\ ${ }^{4}$ Department of Translational Medicine, Division of Hematology, Amedeo Avogadro University of Eastern Piedmont, Novara, \\ Italy \\ Correspondence to: Antonino Neri, e-mail: antonino.neri@unimi.it \\ Marta Lionetti, e-mail: marta.lionetti@unimi.it \\ Keywords: multiple myeloma, plasma cell leukemia, TP53, next-generation sequencing, mutational analysis \\ Received: October 9, $2015 \quad$ Accepted: January 19, $2016 \quad$ Published: February 08,2016
}

\section{ABSTRACT}

The prevalence of TP53 mutations greatly varies between tumor types; in multiple myeloma (MM) they were rarely detected at presentation, while increased frequency was reported with disease progression. Using next-generation sequencing, we analyzed TP53 exons 4-9 in a large representative cohort comprising patients with $M M$ at diagnosis and more aggressive forms of plasma cell (PC) dyscrasia, identifying mutations in 4/129 (3\%) MM, 6/24 (25\%) primary PC leukemia, and 2/10 (20\%) secondary PC leukemia cases. A similar increase in prevalence associated with disease aggressiveness ( $5 \%$, $\mathbf{2 9 . 2 \%}$ and 44\%, respectively) was observed for TP53 deletion. Interestingly, in five patients mutations were not concomitant with TP53 deletion. Furthermore, longitudinal analysis revealed the acquisition of TP53 mutations in three of nineteen cases analyzed at relapse. Identified variants were mostly missense mutations concentrated in the DNA binding domain, only partly reflecting the pattern globally observed in human cancers. Our data confirm that TP53 mutations are rare in MM at presentation and rather represent a marker of progression, similarly to del(17p); however, their occurrence even in absence of deletions supports the importance of their assessment in patients with PC dyscrasia, in terms of both risk stratification and therapeutic implications.

\section{INTRODUCTION}

The tumor suppressor protein $\mathrm{p} 53$, encoded by the TP53 gene at chromosome $17 \mathrm{p} 13$, mediates the response to various stress signals (including DNA damage, oxidative stress, ribonucleotide depletion, and deregulated oncogene expression), many of which are encountered during tumor development and malignant progression [1]. Loss of p53 function, due to TP53 deletions and/or mutations or by defects in the signalling pathways upstream or downstream of p53, is associated with oncogenesis, cancer progression and drug resistance. TP53 is mutated in about half of human cancers, and the prevalence of gene mutations greatly varies between different tumor types.

Recently, whole exome sequencing (WES) analyses in multiple myeloma (MM) [2-5], albeit reporting slightly higher mutational frequencies (probably for the extension of the analysis to the entire coding sequence and the greater sensitivity), confirmed the findings of the early studies [6-10], i.e. that TP53 mutations are relatively rare at presentation (mutation prevalence ranging from $0 \%$ to $9.7 \%$ in representative $\mathrm{MM}$ patients' cohorts). The frequency of mutations increases with disease stage, reaching $25-30 \%$ in plasma cell leukemia (PCL) $[11,12]$, and $80 \%$ in human myeloma cell lines (HMCLs) [13]. 
A strong association has been described between TP53 mutation and $\operatorname{del}(17 \mathrm{p})$ [14]. Deletions, predominantly monoallelic, of chromosome $17 \mathrm{p} 13$ region containing the TP53 gene locus occur in about $10 \%$ of untreated $\mathrm{MM}$ cases [15-17]; the incidence rate reported in PCL ranges from $35 \%$ to $75 \%[12,18]$, and is particularly high (more than 50\%) in HMCLs [19]. 17p13 deletion confers a very negative effect on survival [20], displaying the most powerful cutoff for predicting survival if the deletion is carried by more than $50 \%$ of malignant plasma cells [21]. Finally, a recent study identified TP53 as the critical gene of 17p13 deletion in MM [22].

\section{RESULTS}

We performed next generation sequencing (NGS) of TP53 exons 4-9 on genomic DNA of 151 primary patients with plasma cell dyscrasia, including $129 \mathrm{MM}$ and 12 primary PCL (pPCL) patients at diagnosis, and 10 secondary PCL (sPCL) cases (median depth of coverage $=162 x$ ). The mutational analysis was limited to this portion of the gene coding sequence based on the fact that it contains almost 98\% of TP53 mutations identified in the main published whole genome and exome sequencing studies in MM [2-5]. Twelve additional pPCL samples have been recently subjected to WES analysis [11]. Globally, in the 163 tested patients we identified 14 non-synonymous somatic variants in 12 cases (Table 1, Figure 1). Ten mutations were single nucleotide variations (SNVs), all of which but one (introducing a premature stop codon in PCL-037) were missense mutations. The remaining four mutations were nucleotide deletions involving 2, 6, 10 and 82 base pairs respectively, only one of which (6-bp deletion in PCL037) caused an amino acid deletion without alteration of the reading frame. Exon 8 was the most frequently targeted by mutations ( 5 variants), followed by exons 5 and 7 (3 variants each), and exons 4, 6 and 10 (one variant each), whereas no variants were found in exon 9. Apart from the nonsense mutation W91* in case PCL-037 (localized in the SH3-like/Pro-rich structural motif) and the 10-nt deletion spanning intron 9-exon 10 junction in case PCL017, all other variants targeted the DNA binding domain. In regards to the four nucleotide deletions identified, only one (T155_R156del in PCL-037) is reported in the IARC p53 website (http://www-p53.iarc.fr/index.html) [23], and none has been described in other MM series. In contrast, all ten single nucleotide variations found by us are listed in the dataset of somatic mutations in sporadic cancers of the IARC database. Each of the variants is carried by a single patient in our cohort.

Taking advantage of the most recent WES reports in $\mathrm{MM}$ [2-5], we globally considered the molecular spectrum of TP53 mutations including the results of our present series. We evidenced that mutations cluster in the DNA binding domain; I195 and R273 are the most frequently mutated residues (I195T detected in three cases and I195M in one; R273H in two patients, and R273L and R273C each in one case), followed by P278 (P278S recurring twice, and P278L once), R248 (R248Q and R248W in one patient each) and E285 (E285K in two cases). Contrary to what is globally observed in MM, somatic mutations at codon 195 are not among the most recurrent in human tumors. Notably, the substitution I195T, like other tumorigenic mutations in the $\beta$-sandwich affecting hydrophobic residues in the protein core, was reported to be severely destabilizing [24], determining a half-life of the unfolding of the mutant protein of less than one minute at $37^{\circ} \mathrm{C}$ [25]. Conversely, R273 is one of the six residues identified as hotspots for tumorigenic mutations in human cancers; it is generally targeted by two predominant substitutions, i.e. R273H and R273C, both of which identified in MM cases and preventing DNA binding by the isolated core domain [24]. With regard to the amino acid residue 278 , it is one of the essential amino acids for major groove contacts in the pentamer sequence of the consensus DNA binding site [26]. The substitution E285K is the most common TP53 temperature-sensitive mutation (its wild type TP53 activity is reconstituted at about $32^{\circ} \mathrm{C}$ ) and is also carried by the RPMI-8226 MM cell line $[13,27,28]$. Amino acid substitutions $\mathrm{R} \rightarrow \mathrm{W}$ and $\mathrm{R} \rightarrow \mathrm{Q}$ at the hot spot codon 248 both inactivate the transactivating functions of wild type TP53, although it has been demonstrated that they differently contribute to in vitro malignant behavior of tumor cells through gain-of-function properties [29]. Other codons are targeted by single mutational events in each patient's dataset. Furthermore, virtually all the missense mutations identified in our study are classified as non-functional [23] in the IARC database (see Materials and Methods).

Noteworthy, we detected the occurrence of two concomitant TP53 mutations in two patients of our dataset. In particular, PCL-037 carried the nonsense mutation W91* at a variant allele frequency (VAF) of $47.3 \%$ and a 2-aa deletion (T155_R156del) at a VAF of $49.2 \%$, suggesting the occurrence of both mutations virtually in the entire tumor population (due to the experimental design, it is not possible to determine whether the mutations are carried on two different chromosomes or on the same allele); and MM-213 harbored a 82 nt-deletion (at VAF of $8.2 \%$ ) comprising the last 50 nucleotides of exon 7 and the first 32 nucleotides of intron 7 and putatively originating an in frame amino acid deletion and altered splicing (due to the loss of a splice donor site), and a two-nucleotide deletion (at VAF of $2.6 \%$ ) in exon 8 causing frameshift (A276Lfs*29).

Mutation frequencies were of 3.1\% (4/129), 25\% $(6 / 24)$, and 20\% (2/10) in MM, pPCL and sPCL patients, respectively (Freeman-Halton test, $P=0.0005$ ), in line with the notion that TP53 mutations are associated with aggressive forms of plasma cell dyscrasias and have a role in tumor progression than initiation $[6,7]$. This hypothesis was further supported by TP53 NGS analysis of 19 of our 
Table 1: Summary of TP53 non-synonymous/indel variants identified by NGS in the present dataset

\begin{tabular}{|c|c|c|c|c|c|c|c|}
\hline Variant $^{\circ}$ & $\begin{array}{l}\text { cDNA position } \\
\text { (NM_000546.5) }\end{array}$ & $\begin{array}{l}\text { Amino acid } \\
\text { change }\end{array}$ & $\begin{array}{c}\text { IARC } \\
\text { mut ID }\end{array}$ & $\begin{array}{l}\text { Domain_- } \\
\text { function }\end{array}$ & $\begin{array}{c}\text { Structural } \\
\text { motif }\end{array}$ & $\begin{array}{c}\text { Transacti- } \\
\text { vation class }\end{array}$ & $\begin{array}{c}\text { Mutated samples } \\
\text { (VAF) }\end{array}$ \\
\hline $17: 7673803 \mathrm{G}>\mathrm{A}$ & c. $817 \mathrm{C}>\mathrm{T}$ & $\mathrm{R} 273 \mathrm{C}$ & 3730 & DNA binding & $\mathrm{L} 1 / \mathrm{S} / \mathrm{H} 2$ & non-functional & PCL-030 (100\%) \\
\hline $17: 7674947 \mathrm{~A}>\mathrm{G}$ & c. $584 \mathrm{~T}>\mathrm{C}$ & I195T & 2446 & DNA binding & $\begin{array}{c}\text { NDBL/ } \\
\text { beta-sheets }\end{array}$ & non-functional & PCL-027 (90.9\%) \\
\hline $17: 7673787 \mathrm{G}>\mathrm{A}$ & c. $833 \mathrm{C}>\mathrm{T}$ & P278L & 3817 & DNA binding & $\mathrm{L} 1 / \mathrm{S} / \mathrm{H} 2$ & non-functional & PCL-018 (96.1\%) \\
\hline 17:7670714_7670723del & c.994-8_995del & altered splicing & l & l & l & / & PCL-017 (70\%) \\
\hline $17: 7673810 A>T$ & $c .810 T>A$ & $F 270 L$ & 3682 & DNA binding & $\begin{array}{c}N D B L / \\
\text { beta-sheets }\end{array}$ & non-functional & $M M-281 \_2(96.8 \%)$ \\
\hline $17: 7674245 \mathrm{~T}>\mathrm{C}$ & c. $718 \mathrm{~A}>\mathrm{G}$ & S240G & 3146 & DNA binding & $\mathrm{L} 2 / \mathrm{L} 3$ & non-functional & MM-262 (100\%) \\
\hline $17: 7673781 \mathrm{C}>\mathrm{T}$ & c. $839 \mathrm{G}>\mathrm{A}$ & R280K & 3849 & DNA binding & $\mathrm{L} 1 / \mathrm{S} / \mathrm{H} 2$ & non-functional & PCL-031 (98.52\%) \\
\hline $17: 7675074 \mathrm{C}>\mathrm{T}$ & c. $.538 \mathrm{G}>\mathrm{A}$ & E180K & 2229 & DNA binding & $\mathrm{L} 2 / \mathrm{L} 3$ & $\begin{array}{l}\text { partially } \\
\text { functional }\end{array}$ & PCL-012 (95.82\%) \\
\hline $17: 7675232 \mathrm{G}>\mathrm{T}$ & c. $380 \mathrm{C}>\mathrm{A}$ & S127Y & 1339 & DNA binding & $\mathrm{L} 1 / \mathrm{S} / \mathrm{H} 2$ & non-functional & MM-375 (93.33\%) \\
\hline $17: 7673767 \mathrm{C}>\mathrm{T}$ & c. $853 \mathrm{G}>\mathrm{A}$ & $\mathrm{E} 285 \mathrm{~K}$ & 3932 & DNA binding & $\mathrm{L} 1 / \mathrm{S} / \mathrm{H} 2$ & non-functional & PCL-004 (72.71\%) \\
\hline 17:7675144_7675149delGCGGGT & $\begin{array}{c}\text { c. } 463 \\
\text { 468delACCCGC }\end{array}$ & T155_R156del & 1785 & DNA binding & $\begin{array}{c}\text { NDBL/ } \\
\text { beta-sheets }\end{array}$ & NA & PCL-037 (49.25\%) \\
\hline $17: 7676096 \mathrm{C}>\mathrm{T}$ & c. $273 \mathrm{G}>\mathrm{A}$ & W91* & 922 & $\begin{array}{l}\text { SH3-like/Pro- } \\
\text { rich }\end{array}$ & $\begin{array}{l}\text { SH3-like/ } \\
\text { Pro-rich }\end{array}$ & NA & PCL-037 (47.34\%) \\
\hline $17: 7673788 G>T$ & c. $832 C>A$ & $P 278 T$ & 3810 & DNA binding & $L 1 / S / H 2$ & non-functional & $M M-280 \_2(26.28 \%)$ \\
\hline $17: 7676011 T>C$ & c. $358 A>G$ & $K 120 E$ & 1245 & DNA binding & $L 1 / S / H 2$ & non-functional & PCL-038 (22.11\%) \\
\hline 17:7674149_7674230del & c. $733 \_782+32 \mathrm{del}$ & altered splicing & l & / & l & / & MM-213 (8.22\%) \\
\hline $17: 7674238 \mathrm{C}>\mathrm{T}$ & c. $725 \mathrm{G}>\mathrm{A}$ & $\mathrm{C} 242 \mathrm{Y}$ & 3185 & DNA binding & $\mathrm{L} 2 / \mathrm{L} 3$ & non-functional & MM-343 (10.96\%) \\
\hline 17:7673794_7673795delCA & c. $825 \_826$ delTG & A276Lfs*29 & / & / & / & / & MM-213 (2.65\%) \\
\hline
\end{tabular}

${ }^{\circ}$ Genomic positions based on hg38.

Data were obtained from the IARC p53 website (http://www-p53.iarc.fr/index.html).

Variants indicated in italic were detected in the sample collected at the second timepoint in longitudinally analyzed patients. VAF: variant allele frequency

patients at relapse/leukemic transformation, revealing the acquisition of non-functional missense mutations (undetectable in the corresponding samples analyzed by NGS at diagnosis) in the DNA binding domain in three cases (Table 1, Figures 1 and 2): specifically, the longitudinal analysis detected the substitutions P278T $(\mathrm{VAF}=26.3 \%)$ in the myeloma patient MM-280 at relapse, F270L $(\mathrm{VAF}=97 \%)$ at the time of leukemic transformation in the myeloma patient MM-281, and $\mathrm{K} 120 \mathrm{E}(\mathrm{VAF}=22.1 \%)$ in the pPCL patient PCL-038 at relapse, respectively. Notably, genome-wide DNA copy number data were also available for MM-281, indicating two interstitial deletions of $17 \mathrm{p}$ arm not involving TP53 locus present at sub-clonal level in the sample at onset, and then detecting a larger deletion spanning from $17 \mathrm{p} 12$ to $17 \mathrm{pter}$ in virtually all cells of the later sample (Supplementary Figure S1).

We also tested the association between the occurrence of TP53 mutations and common genetic abnormalities in MM (i.e. chromosomal translocations at $I G H$ locus, hyperdiploidy, deletions at chromosome regions $13 q, 17 p$, and $1 p$, and gain at $1 q)$, for which the entire patients' cohort was characterized by means of fluorescence in situ hybridization (FISH) (Tables 2 and 3). $I G H$ translocations (particularly $M A F$-translocations) were found to be more frequent in TP53-mutated cases compared with the whole series $(92 \%$ versus $50 \%, P=$ $0.0024)$. TP53 mutations were negatively associated with hyperdiploid status (no hyperdiploid cases among the TP53-mutated ones versus $33 \%$ in the entire cohort, $P$ $=0.009$ ); the over-representation of PCL patients within mutated cases could affect these findings, although in part confirmed in other series [30]. However, the low TP53 mutation prevalence in MM did not allow to limit contingency analyses to this class. As regards $17 \mathrm{p}$ deletion, a strong association of gene mutation with the deletion of the remaining allele was observed: in fact, deletion of TP53 locus globally affected $10.6 \%$ of cases $[4.7 \%(6 / 128)$ of MM, $29.2 \%(7 / 24)$ of pPCL and $44.4 \%(4 / 9)$ of sPCL patients respectively], while its prevalence reached $58 \%$ in TP53-mutated subset $(P$ $<0.0001$ ). Overall, TP53 inactivation as a result of gene deletion and/or mutation occurred in $7 \%$ of $\mathrm{MM}, 37.5 \%$ of pPCL and $44.4 \%$ of sPCL patients; in particular, the 
two lesions were simultaneously present respectively in $0.8 \%, 16.7 \%$ and $22.2 \%$ of cases, causing biallelic gene inactivation. A fraction of TP53 mutations co-occurred with variants affecting other MM driver genes (Figure 3) [31-33]. Indeed, two TP53-mutated cases carried also mutations in $D I S 3$, and another one was simultaneously mutated in TP53, NRAS and FAM46C genes. However, TP53 mutations were not positively associated with those of any other gene; on the contrary, the absence of TP53 mutations in KRAS-mutated cases was deemed statistically significant $(P=0.019)$.

Concerning variant allele frequencies, in mutated patients positive for del(17p) VAFs were almost always indicative of the exclusive presence of the mutated allele; on the contrary, in mutated cases at onset and disomic for chromosome 17 VAFs ranged from $2.65 \%$ to $100 \%$, suggesting the occurrence of minor mutated subclones in MM-213 and MM-343; the presence of clonal heterozygous mutations in PCL-037; the predominance of mutated allele in PCL-004; and apparent copy number-neutral loss of heterozigosity in MM-262 (Figure 4). As stated above, in the three patients longitudinally analyzed and showing in the late sample the emergence of TP53 mutations not visible in the earlier sample, VAFs were of $22.1 \%, 26.3 \%$ and $97 \%$, respectively.

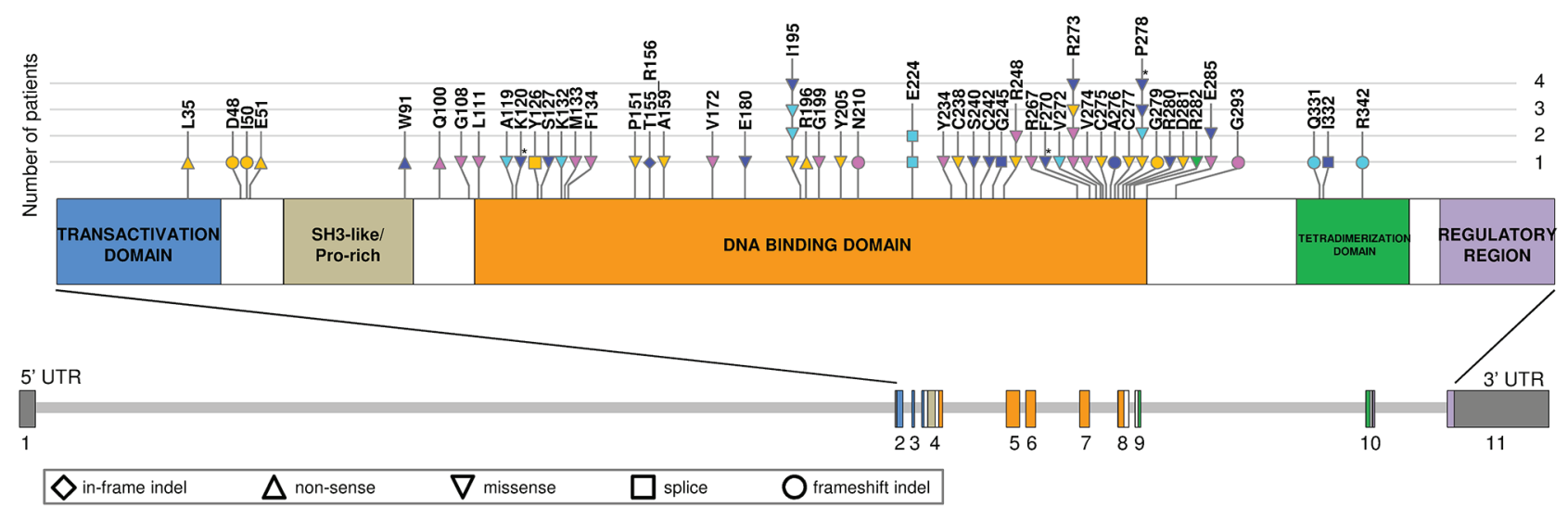

Figure 1: Representation of TP53 mutations identified in MM/PCL patients, including overview of the literature. Amino acid changes caused by mutations are indicated on the scheme of the structural organization of TP53 protein. In the lower part of the figure, schematizing TP53 gene, exons are numbered under the boxes, filled with the color corresponding to the encoded domain. Somatic mutations identified in the present series (blue) and in the main recent MM datasets are depicted (Chapman et al, 2011, and Lohr et al, 2014, yellow; Walker et al, 2012, green and Walker et al, 2015, pink; Bolli et al, 2014, light blue). Mutations identified in the present cohort in patients at relapse are marked by an asterisk. Symbols of mutations are shaped according to their type (see legend in the figure).

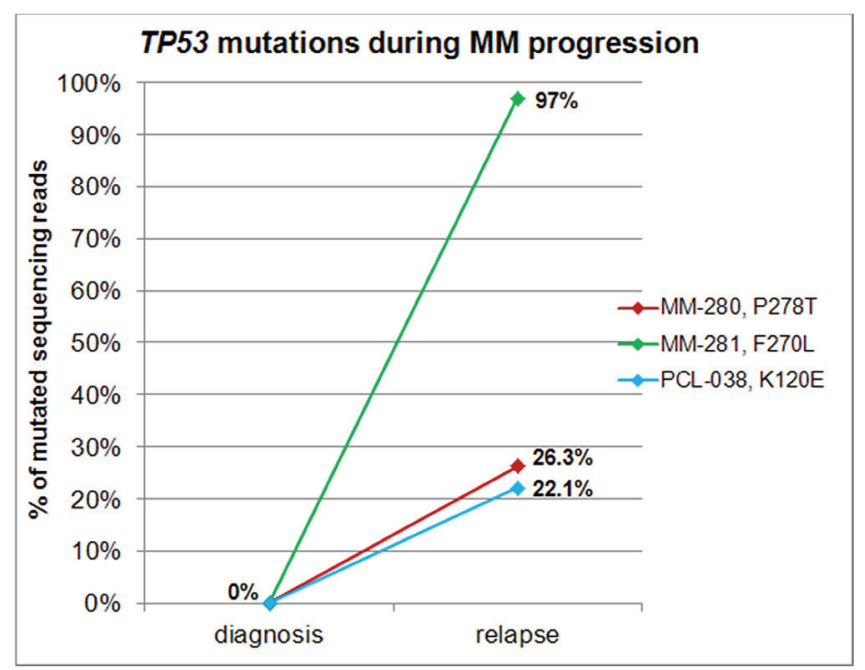

Figure 2: TP53 mutations during disease progression. Variants reported in the legend were acquired during disease progression, being detectable at plotted allele frequencies only in the late sample of longitudinally analyzed patients. 
Table 2: Clinical and molecular characteristics of the $12 \mathrm{MM} / \mathrm{PCL}$ patients carrying TP53 mutations

\begin{tabular}{|c|c|c|c|c|c|c|c|c|c|c|c|c|c|}
\hline Sample & $\begin{array}{l}\text { Disease } \\
\text { stage }^{\S}\end{array}$ & Variant $^{s}$ & $\begin{array}{l}\text { Mutated } \\
\text { reads }(\%)\end{array}$ & AA change & $t(4 ; 14)$ & $t(11 ; 14)$ & $t(14 ; 16)$ & $t(14 ; 20)$ & $\operatorname{del}(13) *$ & $* \operatorname{del}(17 p)^{*}$ & $1 q$ gain* & 1p loss* & $H D^{t}$ \\
\hline MM-213 & MM & $\begin{array}{l}17: 7674149 \_7674230 \mathrm{del}(82) \\
17: 7673794 \_7673795 \mathrm{del} \mathrm{CA}\end{array}$ & $\begin{array}{l}8.2 \% \\
2.6 \%\end{array}$ & $\begin{array}{l}\text { altered splicing } \\
\text { A276L fs*29 }\end{array}$ & - & + & - & - & + & - & - & - & - \\
\hline MM-262 & MM & $17: 7674245 \mathrm{~T}>\mathrm{C}$ & $100 \%$ & S240G & - & - & - & - & - & - & + & - & - \\
\hline MM-343 & $\mathrm{MM}$ & $17: 7674238 \mathrm{C}>\mathrm{T}$ & $11 \%$ & $\mathrm{C} 242 \mathrm{Y}$ & - & + & - & - & - & - & - & - & - \\
\hline MM-375 & MM & $17: 7675232 \mathrm{G}>\mathrm{T}$ & $93.3 \%$ & S127Y & + & - & - & - & - & + & - & - & - \\
\hline PCL-004 & $\mathrm{pPCL}$ & $17: 7673767 \mathrm{C}>\mathrm{T}$ & $72.7 \%$ & E285K & - & - & + & - & - & - & - & - & - \\
\hline PCL-012 & $\mathrm{sPCL}$ & $17: 7675074 \mathrm{C}>\mathrm{T}$ & $95.8 \%$ & E180K & - & - & + & - & - & + & - & - & - \\
\hline PCL-017 & pPCL & 17:7670714_7670723del & $70 \%$ & altered splicing & - & - & + & - & + & + & + & + & - \\
\hline PCL-018 & $\mathrm{pPCL}$ & $17: 7673787 \mathrm{G}>\mathrm{A}$ & $96.1 \%$ & $\mathrm{P} 278 \mathrm{~L}$ & - & + & - & - & + & + & - & - & - \\
\hline PCL-027 & pPCL & $17: 7674947 \mathrm{~A}>\mathrm{G}$ & $90.9 \%$ & I195T & - & + & - & - & - & + & - & - & - \\
\hline PCL-030 & $\mathrm{pPCL}$ & $17: 7673803 \mathrm{G}>\mathrm{A}$ & $100 \%$ & $\mathrm{R} 273 \mathrm{C}$ & - & - & - & + & + & + & - & - & - \\
\hline PCL-031 & sPCL & $17: 7673781 \mathrm{C}>\mathrm{T}$ & $98.5 \%$ & $\mathrm{R} 280 \mathrm{~K}$ & & & & & & & & & \\
\hline PCL-037 & $\mathrm{pPCL}$ & $\begin{array}{l}\text { 17:7675144_7675149delGCGGGT } \\
\text { 17:7676096C }>\mathrm{T}\end{array}$ & $\begin{array}{l}49.2 \% \\
47.3 \%\end{array}$ & $\begin{array}{l}\text { T155_R156del } \\
\text { W91* }\end{array}$ & - & - & + & - & - & + & + & - & - \\
\hline
\end{tabular}

${ }_{\text {} M M}$ : multiple myeloma; pPCL: primary plasma cell leukemia; sPCL: secondary plasma cell leukemia.

\$Genomic positions based on hg38.

*del(13), del(17), 1p loss and 1q gain were determined by FISH.

tHD: presence of the hyperdiploid status on the basis of FISH evaluation criteria.

Table 3: Clinical and molecular characteristics of the $163 \mathrm{MM} / \mathrm{PCL}$ patients analyzed for TP53 mutations

\begin{tabular}{|c|c|c|c|c|c|c|c|}
\hline \multirow[t]{2}{*}{ Characteristic } & \multicolumn{2}{|c|}{ All patients $(n=163)$} & \multicolumn{2}{|c|}{$\begin{array}{l}\text { TP53-wild type } \\
\quad(\mathrm{n}=151)\end{array}$} & \multicolumn{2}{|c|}{$\begin{array}{l}\text { TP53-mutated } \\
(\mathrm{n}=12)\end{array}$} & \multirow[t]{2}{*}{$P$ value } \\
\hline & $\bar{n}$ & $\%$ & $\bar{n}$ & $\%$ & $\bar{n}$ & $\%$ & \\
\hline MM & 129 & 79 & 125 & 83 & 4 & 33 & \multirow{3}{*}{0.0005} \\
\hline pPCL & 24 & 15 & 18 & 12 & 6 & 50 & \\
\hline sPCL & 10 & 6 & 8 & 5 & 2 & 17 & \\
\hline $\operatorname{del}(13 q)$ & 76 & 47 & 71 & 47 & 5 & 42 & \multirow{2}{*}{ n.s. } \\
\hline chr 13 disomic patients & 86 & 53 & 79 & 53 & 7 & 58 & \\
\hline $\operatorname{del}(17 p)$ & 17 & 11 & 10 & 7 & 7 & 58 & \multirow{2}{*}{$<0.0001$} \\
\hline $17 \mathrm{p}$ disomic patients & 144 & 89 & 139 & 93 & 5 & 42 & \\
\hline 1q gain & 65 & 42 & 62 & 44 & 3 & 25 & \multirow{2}{*}{ n.s } \\
\hline 1q disomic patients & 89 & 58 & 80 & 56 & 9 & 75 & \\
\hline $1 \mathrm{p}$ loss & 18 & 13 & 17 & 13 & 1 & 8 & \multirow{2}{*}{ n.s. } \\
\hline $1 \mathrm{p}$ disomic patients & 123 & 87 & 112 & 87 & 11 & 92 & \\
\hline$I G H$ translocation & 80 & 50 & 69 & 46 & 11 & 92 & \multirow{2}{*}{0.0024} \\
\hline no $I G H$ translocation & 81 & 50 & 80 & 54 & 1 & 8 & \\
\hline hyperdiploid & 49 & 33 & 49 & 36 & 0 & 0 & \multirow{2}{*}{0.009} \\
\hline non-hyperdiploid & 100 & 67 & 88 & 64 & 12 & 100 & \\
\hline
\end{tabular}

a'Significance was assessed by Freeman-Halton extension of Fisher's exact test for disease type, and by Fisher's exact test for all other variables. n.s.: not significant. 


\section{DISCUSSION}

In the present study, the use of deep NGS in a large representative cohort of $\mathrm{MM}$ at diagnosis and more aggressive disease stages substantially confirmed the accepted notion that TP53 mutations in MM at presentation are rarely detected, while their frequency increases with disease progression. The enhanced sensitivity of our analysis, in fact, was not accompanied by a substantial increase in the mutation rate observed in MM cases, consistent with the fact that we did not find many mutations at particularly low allele frequency, which could be undetectable by the traditionally used Sanger method. Although we cannot exclude that an even greater depth of coverage would eventually bring out further smaller mutated subclones, this finding is in line with what reported by other recent NGS studies $[2,3,34]$. In extra-medullary MM, TP53 inactivation was significantly more frequent, as a result of both gene mutations and deletions, confirming that these lesions represent late-progression events. Consistently, we noticed the emergence of a mutation in three of 19 MM/PCL patients analyzed at relapse; despite the NGS analysis of the earlier samples, we could not detect at onset minor mutant subclones potentially responsible for relapse. Concerning deletion of chromosome arm $17 \mathrm{p}$, its frequency in intra-medullary MM patients of our series appears to be lower than that generally reported, a finding that could be related to different sample size and patient selection criteria; a strong, albeit not absolute, association of gene mutation with the deletion of the remaining allele was observed also in our series, in line with previously reported data [30]. As regards pPCL, it is noteworthy that a recent WES analysis by our group indicated that TP53 impairment seemed to lie within a more generalized alteration of cell cycle checkpoints, which involved other genes among which the most frequently mutated were $A T M, A T R$, $C D K N 1 A$ and BRCA1 [11]. Furthermore, although less prevalent in MM, mutations in ATM or ATR genes were

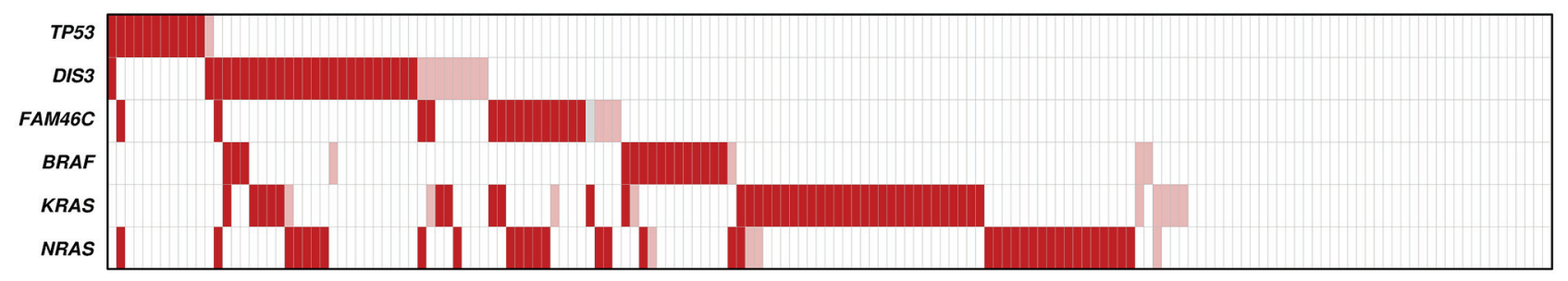

Figure 3: Heat map distribution of TP53, DIS3, FAM46C, BRAF, KRAS and NRAS gene mutations among MM/PCL patients. The rows correspond to the indicated genes, and columns represent individual MM or PCL samples, which are color-coded on the basis of gene status (white: wild-type; light red: Sanger-undetectable mutations; dark red: Sanger-detectable mutations).

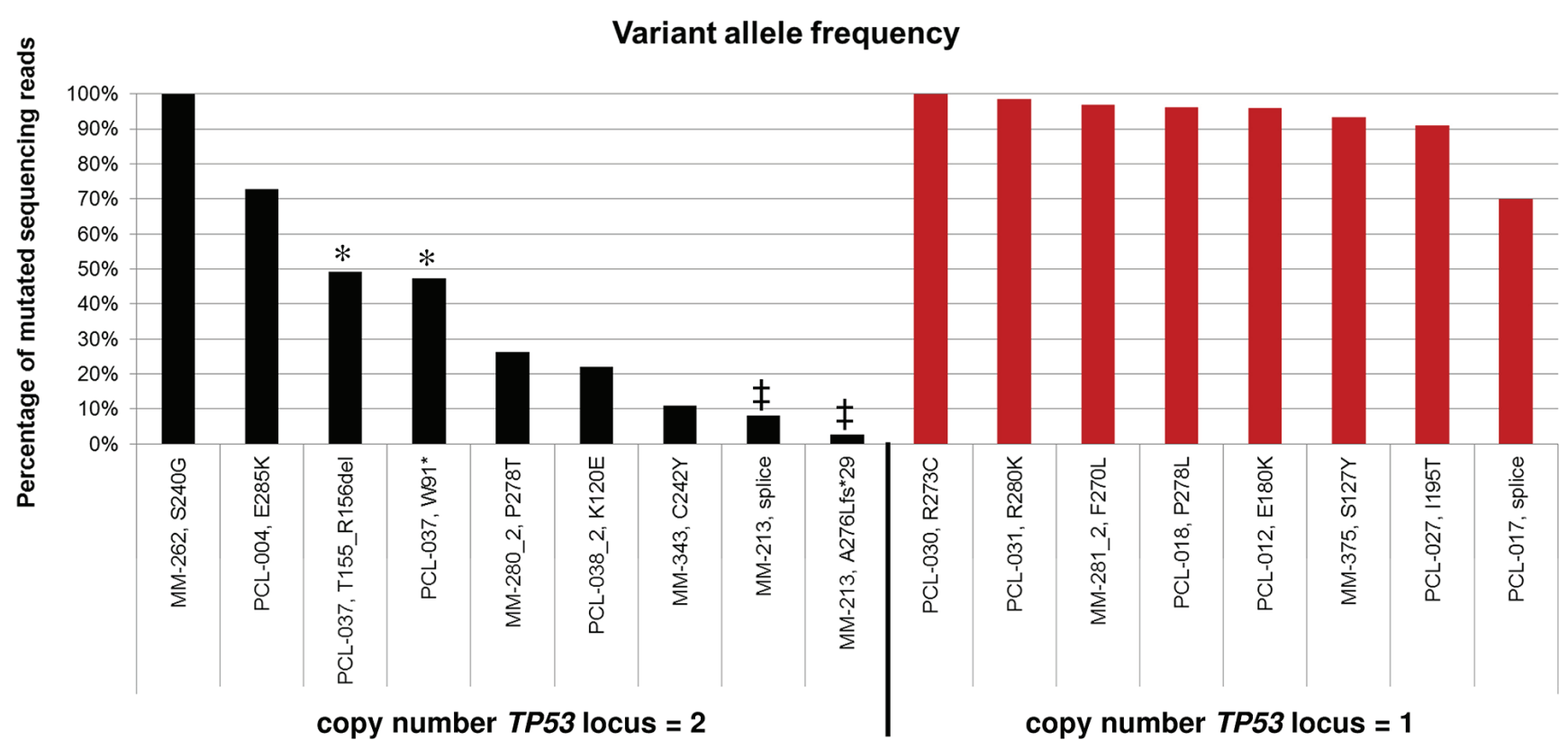

Figure 4: Allele frequency of the TP53 mutations identified by NGS analysis. Horizontal axis: sample id and carried amino acid variant are reported; patients are ordered according to copy number of TP53 locus (as determined by FISH analysis) and decreasing VAF. In case of multiple mutations carried by an individual patient, the bars of the histogram are marked by the same symbol. 
lately reported to be associated with a negative impact on survival of MM patients enrolled onto the NCRI Myeloma XI Trial, in which the inability to deliver an effective apoptotic response to DNA damage represented the most significantly prognostic mutational marker [5].

Concerning the type of variants, unlike Chng et al. [30] and more similarly to what reported by Lodé and colleagues [14] and other more recent papers $[2,3,5]$, most of the mutations identified here were single nucleotide missense mutations. Differently from many tumor suppressor genes, in human cancers TP53 is actually most commonly altered by missense mutations, that not only lead to a loss/diminution of the wild type TP53 activity, but, since TP53 normally acts as a tetramer, may also function as dominant negative inhibitors over any remaining wild type TP53 activity, or even give rise to a more aggressive tumor profile through gain of function activity. Gain of function roles in different cellular processes have indeed been demonstrated for several TP53 mutants also detected in MM/PCL of the present and other published datasets [2-5] (P151S, R248Q, R248W, R273H, R273C, V274F, P278S, and R280K) [35]. MM-associated TP53 mutations are concentrated in the DNA binding domain, and the frequency at which amino acid residues are targeted only in part reflects the one globally observed in human cancers.

In conclusion, our data provide further evidence that mutations of TP53 are rare in MM at diagnosis and rather represent a marker of progression, as well as the deletion of the locus. This would be consistent with the hypothesis that defective TP53 may cause extramedullary disease [20]. Surely, alterations of TP53 identify a high-risk population of patients, even in the context of molecularly comprehensive risk scoring models [5]. Although the close association between mutations and deletions makes it difficult to understand the prognostic contribution of individual lesions $[2,14,30]$, the recently demonstrated haploinsufficiency of the gene [22] may be responsible of TP53 pathway deficiency whenever the cells don't have two intact copies of the gene (as a result of both deletion and mutations). Furthermore, taking into consideration the dominant negative effect or gain of function of many of TP53 mutations, TP53 functionality appears to be even more compromised. In general, the occurrence of mutations even in cases not carrying the deletion supports the importance of their assessment in MM patients, given that many anti-MM drugs induce apoptosis through multiple pathways that are at least in part dependent upon functional TP53 activation.

\section{MATERIALS AND METHODS}

\section{Patients}

The study cohort consisted of a retrospective series of 129 multiple myeloma (MM) and 8 primary plasma cell leukemia (pPCL) cases at onset, and 10 secondary PCL (sPCL), admitted to our Institution from July 2001 to April 2014. Additional 16 pPCL patients belonged to a prospective multicenter clinical trial (RVPCL-PI-350, EudraCT N²008-003246-28) [36]. All the patients included in this study have been previously described [33].

\section{Sample preparation and molecular analyses}

Highly purified ( $\geq 90 \%$ in all cases) plasma cells (PCs) were obtained from bone marrow specimens (collected at the time of diagnosis) using CD138 immunomagnetic microbeads as previously described [37, 38]; 19 cases were re-sampled at relapse/leukemic transformation. Genomic DNA was extracted using Wizard genomic purification DNA kit (Promega Corporation).

\section{Mutation analysis}

NGS of TP53 exons 4-9 (RefSeq NM_000546.5, representing the longer transcript encoding the longest protein isoform) was performed on genomic DNA using the Genome Sequencer Junior instrument (Roche-454 Life Sciences, Penzberg, Germany), as previously described [39]. Further details on primer sequences and sequencing protocol are available in the Supplementary Materials and Methods and Supplementary Table S1. The obtained sequencing reads were mapped to the TP53 human reference sequence (RefSeq NC_000017.11) and analyzed by the Amplicon Variant Analyzer (AVA) software version 3.0 (454 Life Sciences) to establish the variant allele frequency.

The presence of each obtained non-synonymous variant was verified in an independent PCR product by conventional sequencing whenever the sensitivity of the Sanger method was consistent with the VAF. NGS analysis was repeated in case of mutations detected in less than $10 \%$ of sequencing reads. To exclude germline variants, we sequenced the matched normal DNA, when available, or consulted the International Agency for Research on Cancer (IARC) Database (http://www-p53.iarc.fr). Information about the functional relevance of the detected mutations was obtained from IARC database; specifically, a TP53 mutant was classified as "non-functional" if the median of its transcriptional activities measured in reporter assays on eight different promoters containing TP53-binding sequences was lower than 20\% compared to the wild type protein.

\section{Statistical analysis}

Contingency analyses were made using two-sided Fisher's exact test ( $P$ value lower than 0.05 was considered significant). 


\section{ACKNOWLEDGMENTS}

This work was financially supported by grants from: the AIRC Investigator Grants no.10136 (to A.N.) and the Ministero Italiano dell'Istruzione, Università e Ricerca (MIUR) grant 2009PKMYA2 (to A.N.). P.M. is supported by a Research fund from Celgene. K.T. was supported by the Italian Health Minister, Finalized Research for Young Researchers, CUP Project E66110000230001.

\section{CONFLICTS OF INTEREST}

The authors declare that they have no conflict of interest.

\section{REFERENCES}

1. Vousden KH, Lu X. Live or let die: the cell's response to p53. Nat Rev Cancer. 2002; 2:594-604.

2. Bolli N, Avet-Loiseau H, Wedge DC, Van Loo P, Alexandrov LB, Martincorena I, Dawson KJ, Iorio F, NikZainal S, Bignell GR, Hinton JW, Li Y, Tubio JM, et al. Heterogeneity of genomic evolution and mutational profiles in multiple myeloma. Nat Commun. 2014; 5:2997.

3. Lohr JG, Stojanov P, Carter SL, Cruz-Gordillo P, Lawrence MS, Auclair D, Sougnez C, Knoechel B, Gould J, Saksena G, Cibulskis K, McKenna A, Chapman MA, et al. Widespread genetic heterogeneity in multiple myeloma: implications for targeted therapy. Cancer Cell. 2014; 25:91-101.

4. Walker BA, Wardell CP, Melchor L, Hulkki S, Potter NE, Johnson DC, Fenwick K, Kozarewa I, Gonzalez D, Lord CJ, Ashworth A, Davies FE, Morgan GJ. Intraclonal heterogeneity and distinct molecular mechanisms characterize the development of $\mathrm{t}(4 ; 14)$ and $\mathrm{t}(11 ; 14)$ myeloma. Blood. 2012; 120:1077-1086.

5. Walker BA, Boyle EM, Wardell CP, Murison A, Begum DB, Dahir NM, Proszek PZ, Johnson DC, Kaiser MF, Melchor L, Aronson LI, Scales M, Pawlyn C, et al. Mutational Spectrum, Copy Number Changes, and Outcome: Results of a Sequencing Study of Patients With Newly Diagnosed Myeloma. J Clin Oncol. 2015.

6. Corradini P, Inghirami G, Astolfi M, Ladetto M, Voena C, Ballerini P, Gu W, Nilsson K, Knowles DM, Boccadoro M, et al. Inactivation of tumor suppressor genes, p53 and Rb1, in plasma cell dyscrasias. Leukemia. 1994; 8:758-767.

7. Neri A, Baldini L, Trecca D, Cro L, Polli E, Maiolo AT. p53 gene mutations in multiple myeloma are associated with advanced forms of malignancy. Blood. 1993; 81:128-135.

8. Portier M, Moles JP, Mazars GR, Jeanteur P, Bataille R, Klein B, Theillet C. p53 and RAS gene mutations in multiple myeloma. Oncogene. 1992; 7:2539-2543.

9. Preudhomme C, Facon T, Zandecki M, Vanrumbeke M, Lai JL, Nataf E, Loucheux-Lefebvre MH, Kerckaert JP, Fenaux P. Rare occurrence of P53 gene mutations in multiple myeloma. Br J Haematol. 1992; 81:440-443.
10. Willems PM, Kuypers AW, Meijerink JP, Holdrinet RS, Mensink EJ. Sporadic mutations of the p53 gene in multiple myeloma and no evidence for germline mutations in three familial multiple myeloma pedigrees. Leukemia. 1993; 7:986-991.

11. Cifola I, Lionetti M, Pinatel E, Todoerti K, Mangano E, Pietrelli A, Fabris S, Mosca L, Simeon V, Petrucci MT, Morabito F, Offidani M, Di Raimondo F, et al. Wholeexome sequencing of primary plasma cell leukemia discloses heterogeneous mutational patterns. Oncotarget. 2015; 6:17543-17558. doi: 10.18632/oncotarget.4028.

12. Tiedemann RE, Gonzalez-Paz N, Kyle RA, Santana-Davila R, Price-Troska T, Van Wier SA, Chng WJ, Ketterling RP, Gertz MA, Henderson K, Greipp PR, Dispenzieri A, Lacy $\mathrm{MQ}$, et al. Genetic aberrations and survival in plasma cell leukemia. Leukemia. 2008; 22:1044-1052.

13. Mazars GR, Portier M, Zhang XG, Jourdan M, Bataille R, Theillet C, Klein B. Mutations of the p53 gene in human myeloma cell lines. Oncogene. 1992; 7:1015-1018.

14. Lode L, Eveillard M, Trichet V, Soussi T, Wuilleme S, Richebourg S, Magrangeas F, Ifrah N, Campion L, Traulle C, Guilhot F, Caillot D, Marit G, et al. Mutations in TP53 are exclusively associated with $\operatorname{del}(17 \mathrm{p})$ in multiple myeloma. Haematologica. 2010; 95:1973-1976.

15. Avet-Loiseau H, Attal M, Moreau P, Charbonnel C, Garban F, Hulin C, Leyvraz S, Michallet M, Yakoub-Agha I, Garderet L, Marit G, Michaux L, Voillat L, et al. Genetic abnormalities and survival in multiple myeloma: the experience of the Intergroupe Francophone du Myelome. Blood. 2007; 109:3489-3495.

16. Chang H, Qi C, Yi QL, Reece D, Stewart AK. p53 gene deletion detected by fluorescence in situ hybridization is an adverse prognostic factor for patients with multiple myeloma following autologous stem cell transplantation. Blood. 2005; 105:358-360.

17. Schultheis B, Kramer A, Willer A, Hegenbart U, Goldschmidt H, Hehlmann R. Analysis of p73 and p53 gene deletions in multiple myeloma. Leukemia. 1999; 13:2099-2103.

18. Mosca L, Musto P, Todoerti K, Barbieri M, Agnelli L, Fabris S, Tuana G, Lionetti M, Bonaparte E, Sirchia SM, Grieco V, Bianchino G, D'Auria F, et al. Genome-wide analysis of primary plasma cell leukemia identifies recurrent imbalances associated with changes in transcriptional profiles. Am J Hematol. 2013; 88:16-23.

19. Lombardi L, Poretti G, Mattioli M, Fabris S, Agnelli L, Bicciato S, Kwee I, Rinaldi A, Ronchetti D, Verdelli D, Lambertenghi-Deliliers G, Bertoni F, Neri A. Molecular characterization of human multiple myeloma cell lines by integrative genomics: Insights into the biology of the disease. Genes Chromosomes \& Cancer. 2007; 46:226-238.

20. Fonseca R, Bergsagel PL, Drach J, Shaughnessy J, Gutierrez N, Stewart AK, Morgan G, Van Ness B, Chesi M, Minvielle S, Neri A, Barlogie B, Kuehl WM, et al. International Myeloma Working Group molecular 
classification of multiple myeloma: spotlight review. Leukemia. 2009; 23:2210-2221.

21. An G, Li Z, Tai YT, Acharya C, Li Q, Qin X, Yi S, Xu Y, Feng X, Li C, Zhao J, Shi L, Zang M, et al. The impact of clone size on the prognostic value of chromosome aberrations by fluorescence in situ hybridization in multiple myeloma. Clin Cancer Res. 2015; 21:2148-2156.

22. Teoh PJ, Chung TH, Sebastian S, Choo SN, Yan J, Ng SB, Fonseca R, Chng WJ. p53 haploinsufficiency and functional abnormalities in multiple myeloma. Leukemia. 2014; 28:2066-2074.

23. Petitjean A, Mathe E, Kato S, Ishioka C, Tavtigian SV, Hainaut P, Olivier M. Impact of mutant p53 functional properties on TP53 mutation patterns and tumor phenotype: lessons from recent developments in the IARC TP53 database. Human Mutation. 2007; 28:622-629.

24. Bullock AN, Henckel J, Fersht AR. Quantitative analysis of residual folding and DNA binding in mutant p53 core domain: definition of mutant states for rescue in cancer therapy. Oncogene. 2000; 19:1245-1256.

25. Friedler A, Veprintsev DB, Hansson LO, Fersht AR. Kinetic instability of p53 core domain mutants: implications for rescue by small molecules. J Biol Chem. 2003; 278:24108-24112.

26. Brachmann RK, Vidal M, Boeke JD. Dominant-negative p53 mutations selected in yeast hit cancer hot spots. Proc Natl Acad Sci U S A. 1996; 93:4091-4095.

27. Christgen M, Noskowicz M, Heil C, Schipper E, Christgen H, Geffers R, Kreipe H, Lehmann U. IPH-926 lobular breast cancer cells harbor a p53 mutant with temperature-sensitive functional activity and allow for profiling of p53-responsive genes. Lab Invest. 2012; 92:1635-1647.

28. Jia LQ, Osada M, Ishioka C, Gamo M, Ikawa S, Suzuki T, Shimodaira H, Niitani T, Kudo T, Akiyama M, Kimura N, Matsuo M, Mizusawa H, et al. Screening the p53 status of human cell lines using a yeast functional assay. Mol Carcinog. 1997; 19:243-253.

29. Yoshikawa K, Hamada J, Tada M, Kameyama T, Nakagawa K, Suzuki Y, Ikawa M, Hassan NM, Kitagawa Y, Moriuchi T. Mutant p53 R248Q but not R248W enhances in vitro invasiveness of human lung cancer NCI-H1299 cells. Biomed Res. 2010; 31:401-411.

30. Chng WJ, Price-Troska T, Gonzalez-Paz N, Van Wier S, Jacobus S, Blood E, Henderson K, Oken M, Van Ness B, Greipp P, Rajkumar SV, Fonseca R. Clinical significance of TP53 mutation in myeloma. Leukemia. 2007; 21:582-584.

31. Barbieri M, Manzoni M, Fabris S, Ciceri G, Todoerti K, Simeon V, Musto P, Cortelezzi A, Baldini L, Neri A,
Lionetti M. Compendium of FAM46C gene mutations in plasma cell dyscrasias. Br J Haematol. 2015. doi: 10.1111/ bjh.13793.

32. Lionetti M, Barbieri M, Todoerti K, Agnelli L, Fabris S, Tonon G, Segalla S, Cifola I, Pinatel E, Tassone P, Musto P, Baldini L, Neri A. A compendium of DIS3 mutations and associated transcriptional signatures in plasma cell dyscrasias. Oncotarget. 2015; 6:26129-26141. doi: 10.18632/oncotarget.4674.

33. Lionetti M, Barbieri M, Todoerti K, Agnelli L, Marzorati S, Fabris S, Ciceri G, Galletti S, Milesi G, Manzoni M, Mazzoni M, Greco A, Tonon G, et al. Molecular spectrum of BRAF, NRAS and KRAS gene mutations in plasma cell dyscrasias: implication for MEK-ERK pathway activation. Oncotarget. 2015; 6:24205-24217. doi: 10.18632/ oncotarget.4434.

34. Kortum KM, Langer C, Monge J, Bruins L, Egan JB, Zhu YX, Shi CX, Jedlowski P, Schmidt J, Ojha J, Bullinger L, Liebisch P, Kull M, et al. Targeted sequencing using a 47 gene multiple myeloma mutation panel $(\mathrm{M}(3) \mathrm{P})$ in $-17 \mathrm{p}$ high risk disease. Br J Haematol. 2015; 168:507-510.

35. Muller PA, Vousden KH. Mutant p53 in cancer: new functions and therapeutic opportunities. Cancer Cell. 2014; 25:304-317.

36. Musto P, Simeon V, Martorelli MC, Petrucci MT, Cascavilla N, Di Raimondo F, Caravita T, Morabito F, Offidani M, Olivieri A, Benevolo G, Mina R, Guariglia R, et al. Lenalidomide and low-dose dexamethasone for newly diagnosed primary plasma cell leukemia. Leukemia. 2014; 28:222-225.

37. Fabris S, Agnelli L, Mattioli M, Baldini L, Ronchetti D, Morabito F, Verdelli D, Nobili L, Intini D, Callea V, Stelitano C, Lombardi L, Neri A. Characterization of oncogene dysregulation in multiple myeloma by combined FISH and DNA microarray analyses. Genes Chromosomes Cancer. 2005; 42:117-127.

38. Mattioli M, Agnelli L, Fabris S, Baldini L, Morabito F, Bicciato S, Verdelli D, Intini D, Nobili L, Cro L, Pruneri G, Callea V, Stelitano C, et al. Gene expression profiling of plasma cell dyscrasias reveals molecular patterns associated with distinct IGH translocations in multiple myeloma. Oncogene. 2005; 24:2461-2473.

39. Lionetti M, Fabris S, Cutrona G, Agnelli L, Ciardullo C, Matis S, Ciceri G, Colombo M, Maura F, Mosca L, Gentile M, Recchia AG, Ilariucci F, et al. High-throughput sequencing for the identification of NOTCH1 mutations in early stage chronic lymphocytic leukaemia: biological and clinical implications. Br J Haematol. 2014; 165:629-639. 